\title{
THE SEMINIFEROUS TUBULES IN DASYURID MARSUPIALS
}

\author{
P. WOOLLEY \\ Department of Zoology, La Trobe University, Melbourne, Australia
}

(Received 3rd January 1975)

\begin{abstract}
Summary. The morphology of the seminiferous tubules of dasyurid marsupials has been investigated in seven species. The tubules are large in diameter, ranging from 0.36 to $0.52 \mathrm{~mm}$, and the total length of the tubules in the testis is small $(<1 \mathrm{~m})$. In dissected testes, most tubules were found to be in the form of simple loops and the number of loops ranged from one to four. Each loop had two openings into the duct draining the testis. There was only a single duct from the testis in the dasyurids examined. The large diameter, simple form and low number of tubules in the testis of these dasyurid marsupials make them unique among mammals which have been studied in this respect.
\end{abstract}

\section{INTRODUCTION}

In the course of other studies on the reproductive biology of various species of dasyurid marsupials, it was noted that the diameter of the seminiferous tubules in histological sections was considerably larger, both in absolute terms and in relation to the size of the testis, than in other marsupials and eutherian mammals, including common laboratory and domestic species and man. This observation suggested that either the total number of tubules, or the total length of the tubules in the testis of dasyurid marsupials might be less than in these other mammals. It was also noted that there was only a single duct from the testis in the dasyurids examined.

This paper reports observations on the size, number and form of the seminiferous tubules, and the connection of the tubules to the duct in seven species of dasyurid marsupials.

\section{MATERIALS AND METHODS}

The species of dasyurid marsupials examined were Antechinomys spenceri, Sminthopsis crassicaudata, Sminthopsis leucopus, Antechinus stuartii, Dasycercus cristicauda, Dasyuroides byrnei and Sarcophilus harrisii. The testes and epididymides of sexually mature males were removed from the scrotum immediately after the animals were killed. Usually one testis and epididymis was placed in saline for dissection and one in Bouin's fixative for histological examination. Occasionally, both testes from the one animal were dissected while fresh, or both were fixed. 
Testes to be dissected were first separated from the epididymis, the duct being cut close to the point of entry into the epididymis. The thick tunica albuginea of the testis was then removed except for a small portion around the duct at the anterior end. The testis was covered with saline and, using watch-maker's forceps, the seminiferous tubules were cleared of surrounding tissues under the dissecting microscope. Testes that were to be examined histologically were also separated from the epididymis and cut into anterior and posterior halves. The tunica albuginea was removed from the anterior half, the duct being cut close to the testis before it penetrated the tunica albuginea. Serial sections of the anterior half of each testis were cut at $10 \mu \mathrm{m}$ and stained with haematoxylin and eosin. A Leitz drawing mirror attached to a microscope was used to project the sections to make outline drawings of the duct and the connections of the seminiferous tubules to it. From the drawings, a count was made of the number of connections between the tubules and the duct in each testis.

The diameter of the seminiferous tubules in histological sections of thirteen testes from nine individuals of five species $(A$. spenceri, S. crassicaudata, S. leucopus, $D$. byrnei and $S$. harrisii) in which spermatogenesis was taking place was measured using a microscope with a measuring eyepiece calibrated with a stage micrometer. The average of two diameters of ten transverse sections of the tubules was obtained for each testis.

The length of the seminiferous tubules in one testis from each of four species ( $A$. spenceri, $A$. stuartii, D. cristicauda and $D$. byrnei) was obtained in the following way. The dissected testis was photographed and the negative projected in a photographic enlarger. A large outline drawing of the tubules was made and the length of the tubules in the drawing measured with a registering map measurer. The map measurer was calibrated against a millimetre scale which was photographed with the testis and marked on the drawing.

\section{RESULTS}

In testes from which the tunica albuginea had been removed, the duct was seen to emerge from among the seminiferous tubules close to the anterior pole and to lie free for a short distance before penetrating the tunica (Pl. 1, Fig. 1). Superficially the seminiferous tubules did not appear to be arranged in lobules, and lobulation was not apparent on dissection of the testes of the seven species examined. Separation of the tubules in fresh testes showed that they made connection with the duct in the anterior end of the testis. The ends of the tubules tapered before joining the short fine terminal branches of the duct (Pl. 1, Fig. 2). The tapered region of the tubule was more opaque than the remainder of the tubule and the duct. Each tubule usually had two openings into the duct and when the tubules were separated they appeared as simple loops. The testes of A. spenceri and S. crassicaudata contained only a single loop (Pl. 1, Fig. 3). Two, three or four loops were found in the testes of other species examined (see Pl. 1, Fig. 4). Not all the testes dissected showed this simple arrangement of tubules. In one, a tubule opened at one end into the duct and at the other end anastomosed with a loop (Pl. 1, Fig. 5). In another, it appeared that each end of a tubule anastomosed with a different loop (Pl. 1, Fig. 6). This arrangement could also be 


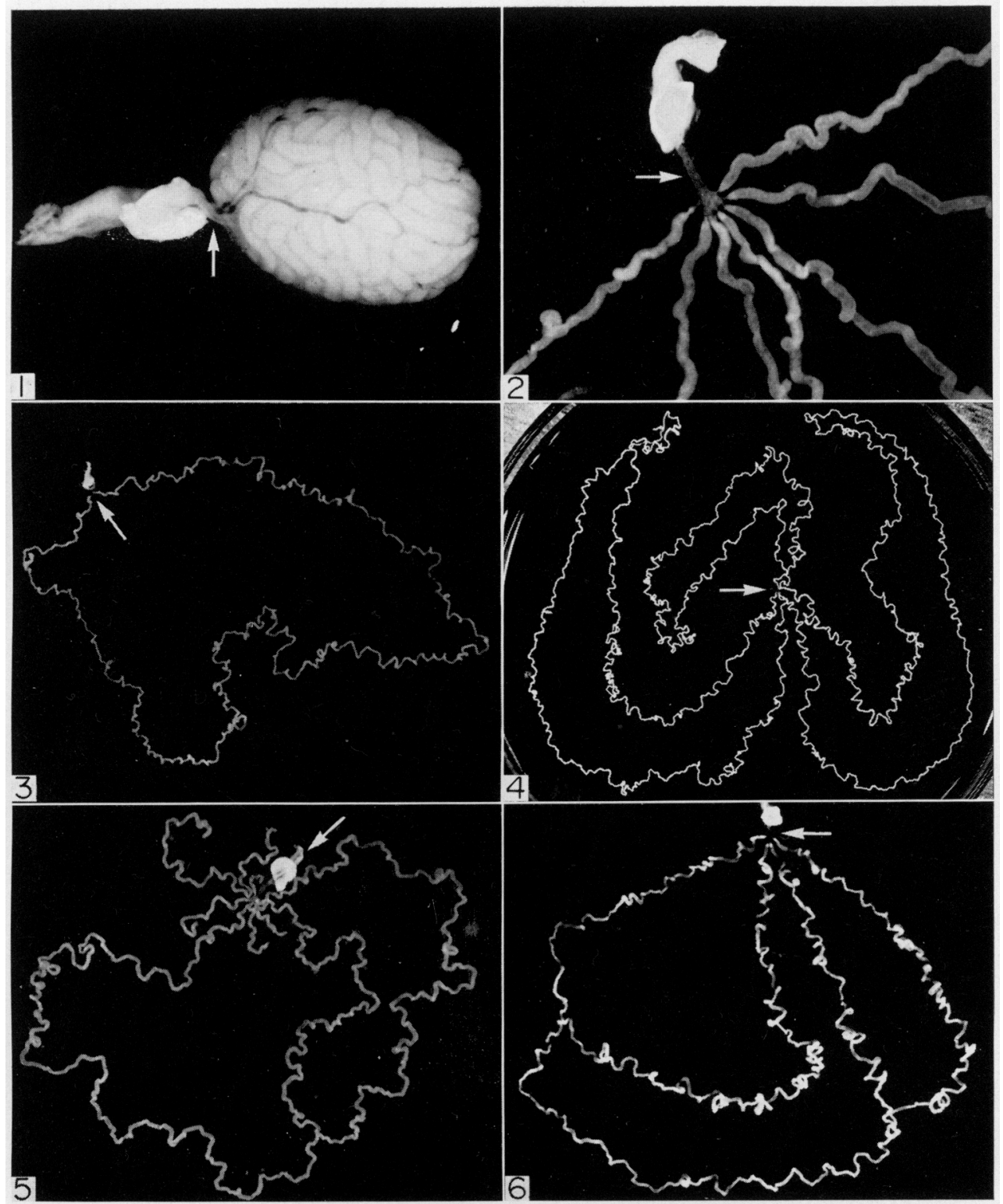

In each figure, the arrow points to the duct. The specimen number for each species is shown in parentheses in the figure legend.

Fu. 1. 'lestis of Antechimomys spenceri (2a) with tunica albuginea removed.

lis. 2. Comnections of the seminilerous tubules to the efferent duct in the left testis of Daspwoides bymei (13). (One of the eight connections was broken and is not shown.

Fia. 3. Single loop in the testis of Antechinomps spenceri (2a).

lis. 4. Three loops in the right testis of Dasyuroides bymei (135).

Fus, 5. Arangement of the tubules in the left testis of Dasyurides byme (10) showing a tubule joining the duct at one end and a loop at the other end. The other three loops in the testis have been remored except for their terminal portions.

fis. 6. Arrangement of the tubules in the left testis of Intechimus stuartio (192) showing a tubule anastomosing with two loops.

(Facing fo. 256 i 
Pl. I'1 :

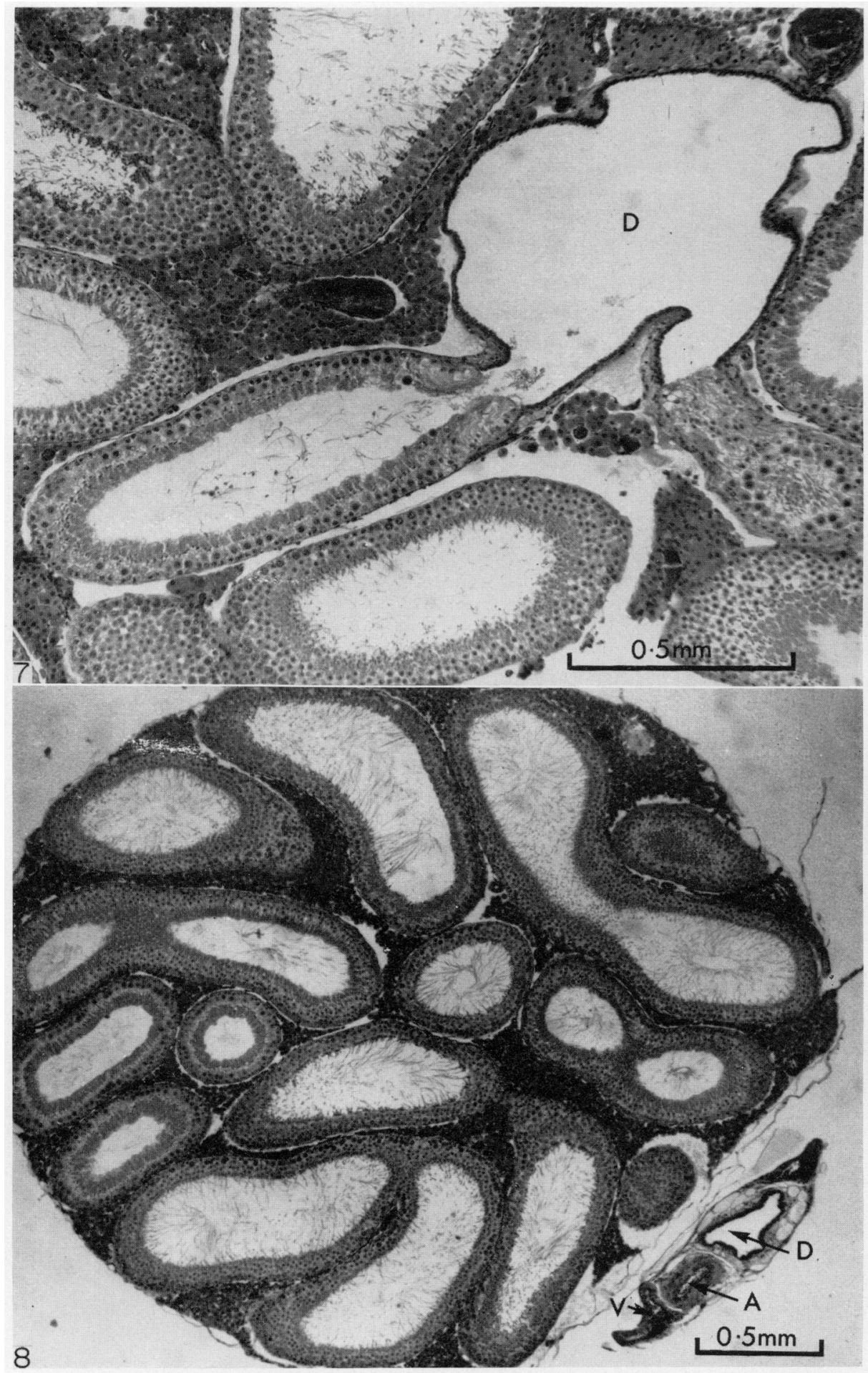

Facing /1. 257 
interpreted as a single loop and two tubules each opening at one end into the duct and at the other into the loop.

In histological sections of the testes, the duct was seen to be lined with a single layer of flattened, non-ciliated cells with dark-staining nuclei (Pl. 2, Fig. 7). Spermatogenic cells were absent from the tapered ends of the seminiferous tubules (tubuli recti) which were lined with tall pale-staining cells with nuclei similar to those of the Sertoli cells. The number of connections between tubules and the duct in the testes which were sectioned ranged from two in $A$. spenceri and $S$. crassicaudata to a maximum of ten in one testis of $D$. byrnei and one of $S$. harrisii. A transverse section of the whole testis with the duct lying beside it is shown in Pl. 2, Fig. 8. The large size of the tubules, both in absolute terms and in relation to the size of the testis can be seen.

Table 1 summarizes the data obtained on the number of connections between the tubules and duct in both dissected and sectioned testes, the form and length of the tubules in dissected testes and the diameter in section of tubules from testes showing spermatogenesis. As an indication of the relative sizes of the various species studied, the body weight of the individuals used is given.

\section{DISCUSSION}

The morphology of the seminiferous tubules of a variety of mammals has been investigated using the techniques of teasing and of reconstruction from serial sections. With these methods it has been found that the simplest form of the seminiferous tubules is a single arch, or loop, with two openings into the rete testis. Frequently however, the tubules are branched and interconnected and they may have more than two openings into the rete.

Previously, the entire testis has been dissected only in the mouse (Hirota, 1952a). The mouse testis was found to contain from eight to thirteen seminiferous tubules, with from 21 to 30 openings into the rete. From four to eleven of the tubules were single arches and from one to four 'double arches' with three limbs each. Three tubules were found with four limbs and one with five. Four 'ring' anastomoses were observed.

Individual tubules have been dissected from the testis of the monkey (Hirota, 1952b), man (Johnson, 1934; Hirota, 1955a) and rabbit (Huber \& Curtis, 1913; Hirota, 1955b) and single arched and more complex branched tubules were seen in all these species.

By reconstruction from serial sections, the number of seminiferous tubules in the testis of the rat and of two marsupials has been determined. Clermont \& Huckins (1961) found twenty tubules, each with two openings into the rete in one adult rat testis. Up to 31 sex cords, from which the seminiferous tubules develop, were seen in testes from rat embryos. Some of the sex cords were

Fia. 7. Section of the testis of Dasyuroides byrnei showing two connections between the seminiferous tubules and the duct. $\mathrm{D}=$ duct.

FIG. 8. Transverse section of the testis of Dasyuroides byrnei to show the size of the tubules relative to the testis. $\mathrm{D}=$ duct; $\mathrm{A}=$ testicular artery; $\mathrm{V}=$ testicular vein. 


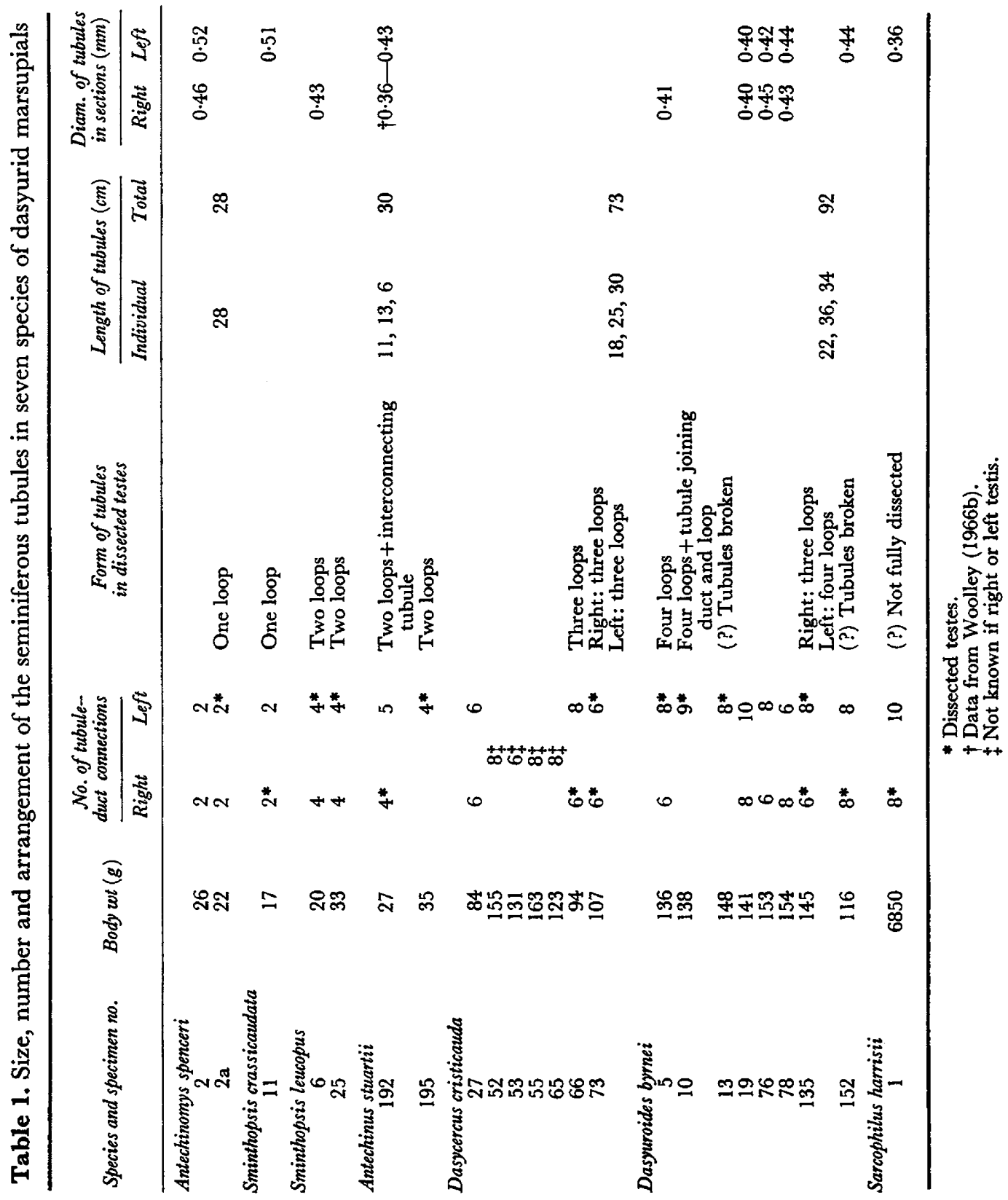


branched. These observations suggest that more than twenty tubules, some branched, might be found in the adult rat testis. In the marsupial, Perameles obesula, deBurlet (1921) found that the testis of one pouch young contained six single loops and one three-limbed loop, with fifteen connections between the tubules and the single duct draining the testis. He also found that the testis of a $20-\mathrm{mm}$ pouch young of a marsupial which he thought might be Didelphis contained only two single loops, with four connections to the collecting duct. In four older stages of Didelphis pouch young, a much greater number of endings of seminiferous tubules connecting with a single duct were observed. deBurlet was also able to estimate from sections the number of tubules in the testis of another marsupial, Halmaturus benetti (= Macropus rufogriseus), to be between 200 and 300 . In this species the tubules were found to converge and end at the inner surface of a horseshoe-shaped rete area.

By comparison with most of the species mentioned above the testes of the dasyurid marsupials examined in the present study are relatively simple structures with a small number of tubules, most of which are in the form of single loops. Also, the number of connections between the seminiferous tubules and the duct system is lower. Only the suspected Didelphis pouch young had such a simple testis, which suggests that the identification may have been incorrect.

The testes of the dasyurid marsupials examined were found to be drained by a single duct, the terminal branches of which connect directly with the seminiferous tubules. Whether or not this duct represents a single rete tubule, as suggested by the work of Fraser (1919), or a continuation of the Wolffian duct into the testis as suggested by van den Broek (1906), cannot be determined from the material examined in the present study. The histological appearance of the duct suggests, however, that it may be a rete tubule and not an efferent tubule of mesonephric origin. Gier \& Marion (1970) state that the rete tubules are comprised of non-ciliated cuboidal to squamous cells that normally stain intensely with haematoxylin, and that the vasa efferentia contain ciliated columnar to pseudostratified columnar epithelial cells. The former was the appearance in the dasyurids examined. Fraser (1919) noted that the single duct of Didelphys aurita had similarly darkly staining walls. A single duct draining the testis was also found by Fraser in Metachirus opossum, Dasyurus viverrinus and in a Perameles 'embryo' and she considered that the rete testis in all polyprotodont marsupials was probably represented by a single duct which connected with a number of tubules of mesonephric origin in the epididymis. In Didelphis virginiana, van den Broek (1906), Chase (1939), and deBurlet (1921) report the occurrence of a single duct connecting the tubules with the epididymis, as in other polyprotodont marsupials, but in three specimens studied by Ladman (1967) from one to three ducts with the histological appearance of vasa efferentia were found. These apparently conflicting observations suggest that the urinogenital connection in this species may occur outside the body of the epididymis, and not within it, as suggested by Fraser. Multiple ducts of rete origin were found in Trichosurus vulpecula by Fraser (1919) and she suggested that this was the case in other diprotodont marsupials, including Phascolarctos. Multiple ducts were found in Macropus eugenii (Setchell, 1970) 
and in this species and Trichosurus vulpecula, according to Setchell, the seminiferous tubules open into a horseshoe shaped rete extending down the epididymal and free margins of the testis. In eutherian mammals the seminiferous tubules open into a rete, which is drained by a number of ducts, and is variously situated in the testis in different species.

The diameter of active seminiferous tubules is greater in dasyurids than in all other species for which information could be found. Bascom \& Osterud (1925) measured the diameter of the tubules in mature specimens of the albino mouse, albino rat, guinea-pig, Belgian hare, dog, man, pig, sheep and bull and found that the diameter ranged from $0.1834 \mathrm{~mm}$ in man to $0.2654 \mathrm{~mm}$ in the albino rat. No direct relationship between the tubule diameter and the size of the adult animal was found. The diameter of the seminiferous tubules of various wild species of eutherian mammals falls within the above range. Among marsupials, the diameter of the tubules has been recorded for the opossum, Didelphis virginiana $(0.23$ to $0.25 \mathrm{~mm}$, Moore \& Morgan, 1942), the possum, Trichosurus vulpecula $(0.226$ to $0.288 \mathrm{~mm}$, Smith et al., 1969), the red kangaroo, Megaleia rufa (between 0.20 and $0.25 \mathrm{~mm}$, Sharman \& Calaby, 1964) and the grey kangaroos, Macropus giganteus and $M$. fuliginosus $(0.18$ to $0.32 \mathrm{~mm}$, Poole, 1973). In all these species, the diameter of the seminiferous tubules is less than in the dasyurids examined, in which the diameter ranged from 0.36 to $0.52 \mathrm{~mm}$.

The total length of the seminiferous tubules in the testes of dasyurid marsupials ranged from 28 to $92 \mathrm{~cm}$ and is less than in other mammals. Knepp (cited in Asdell, 1964) determined the total length of the tubules in eighteen species, including one marsupial (Macropus robustus), and it ranged from $27 \mathrm{~m}$ in the cat to over $10,000 \mathrm{~m}$ in the sheep. Hirota (1952a) measured the total length of the tubules of the mouse from photographs of dissected testes and found that it averaged $1.792 \mathrm{~m}$. Bascom \& Osterud (1925) calculated the length of the tubules in the species (listed above) in which they measured the diameter of the tubules. The total length of the tubules ranged from $1.67 \mathrm{~m}$ in the albino mouse to $6312 \mathrm{~m}$ in the pig, the smaller species having a greater length of tubules per unit of body weight than the larger ones, e.g. the mouse about $100 \mathrm{~cm} / 10 \mathrm{~g}$ and the bull $10 \mathrm{~cm} / 10 \mathrm{~g}$. A similar relationship was found for the four species of dasyurids in which the total tubule length was determined, e.g. A. spenceri, $12.7 \mathrm{~cm} / 10 \mathrm{~g}$ and $D$. byrnei, $6.3 \mathrm{~cm} / 10 \mathrm{~g}$.

The large diameter, simple form and low number of seminiferous tubules in the testes of the dasyurid marsupials examined make them unique among mammals that have been studied in this respect. The relative ease with which the tubules can be separated and intact complete tubules obtained would seem to offer advantages over other species currently used for studies in vitro of the physiology of the testis tubules of mammals. In addition, dasyurid marsupials are seasonal breeders, and, with a knowledge of the reproductive cycle, it would be possible to select animals at particular stages of the spermatogenic cycle to suit experimental requirements. For example, A. stuartii has only one short breeding season in the normal lifespan of the male of just under 1 year, and, as the animals mature, different cell associations are found in the seminiferous tubules (Woolley, 1966a, b). At approximately 5 months of age the seminiferous tubules contain only Sertoli cells and spermatogonia; at 7 months spermatocytes 
are also present; at 9 months the tubules contain Sertoli cells and all the cell types of the germinal epithelium except spermatogonia; at 10 months the tubules are also largely depleted of spermatocytes; and after the mating period, the seminiferous tubules of males maintained in the laboratory beyond their normal lifespan contain only Sertoli cells.

\section{REFERENCES}

Asdell, S.A. (1964) Patterns of Mammalian Reproduction, 2nd edn. Constable, London.

Bascom, K.F. \& Osterud, H.L. (1925) Quantitative studies on the testicle. II. Pattern and total tubule length in the testicles of certain common mammals. Anat. Rec. 31, 159-169.

Chase, E.B. (1939) The reproductive system of the male opossum, Didelphis virginiana Kerr and its experimental modification. F. Morph. 65, 215-239.

Clermont, Y. \& Huckins, C. (1961) Microscopic anatomy of the sex cords and seminiferous tubules in growing and adult male albino rats. Am. F. Anat. 108, 79-97.

DEBurlet, H.M. (1921) Zur Entwicklung und Morphologie des Säugerhodens. II. Marsupialer. Z. Anat. EntwGesch. 61, 19-31.

Fraser, E.A. (1919) The development of the urogenital system in the Marsupialia, with special reference to Trichosurus vulpecula. Part II. J. Anat. 53, 97-129.

Gier, H.T. \& Marion, G.B. (1970) Development of the mammalian testis. In The Testis, Vol. 1, pp. 1-45. Eds. A. D. Johnson, W. R. Gomes and N. L. VanDemark. Academic Press, New York.

Hirota, S. (1952a) The morphology of the seminiferous tubules. 1. The seminiferous tubules of the mouse. Kyushu Mem. med. Sci. 3, 121-128.

Hirota, S. (1952b) The morphology of the seminiferous tubules. II. The seminiferous tubules of the monkey. Kyushu Mem. med. Sci. 3, 129-136.

Hirota, S. (1955a) The morphology of the seminiferous tubules. III. The seminiferous tubules of man. Kyushu F. med. Sci. 6, 180-187.

Hirota, S. (1955b) The morphology of the seminiferous tubules. IV. The seminiferous tubules of the rabbit. Kyushu 7. med. Sci. 6, 188-190.

Hurber, G.C. \& CurTis, G.M. (1913) The morphology of the seminiferous tubules of mammalia. Anat. Rec. 7, 207-219.

Johnson, F.P. (1934) Dissections of human seminiferous tubules. Anat. Rec. 59, 187-199.

Ladman, A.J. (1967) Fine structure of the ductuli efferentes in the opossum. Anat. Rec. 157, 559-575.

Moore, C.R. \& MoRgAN, C.F. (1942) Responses of the testis to androgenic treatments. Endocrinology 30, 990-999.

Poole, W.E. (1973) A study of breeding in grey kangaroos, Macropus giganteus Shaw and M. fuliginosus (Desmarest), in central New South Wales. Aust. F. Zool. 21, 183-212.

SeTcheLl, B.P. (1970) Testicular blood supply, lymphatic drainage, and secretion of fluid. In The Testis, Vol. 1, pp. 101-239. Eds. A. D. Johnson, W. R. Gomes and N. L. VanDemark. Academic Press, New York.

Sharman, G.B. \& Calaby, J.H. (1964) Reproductive behaviour in the red kangaroo, Megaleia rufa, in captivity. C.S.I.R.O. Wildl. Res. 9, 58-85.

SmIth, M.J., BRown, B.K. \& Frith, H.J. (1969) Breeding of the brush-tailed possum, Trichosurus vulpecula (Kerr), in New South Wales. C.S.I.R.O. Wildl. Res. 14, 181-193.

VAN DEN BROEK, A.J.P. (1906) On the relation of the genital ducts to the genital gland in marsupials. Proc. K. ned. Akad. Wet. 396-402.

Woolley, P. (1966a) Reproduction in Antechinus spp. and other dasyurid marsupials. Symp. zool. Soc. Lond. 15, 281-294.

Woolley, P. (1966b) Reproductive biology of Antechinus stuartii Macleay (Marsupialia: Dasyuridae). Ph.D. thesis, Australian National University, Canberra. 